\title{
Immune-mediated necrotizing myopathy
}

INSERM

\section{Source}

INSERM. (1999). Orphanet: an online rare disease and orphan drug data base. Immunemediated necrotizing myopathy. ORPHA:206569

Necrotizing autoimmune myopathy (NAM) is a rare form of idiopathic inflammatory myopathy characterized clinically by acute or subacute proximal muscle weakness, and histopathologically by myocyte necrosis and regeneration without significant inflammation. 